\title{
Using Markers and Field Evaluation to Identify the Source of Eyespot Resistance Gene Pch1 in the Collection of Wheat Breeding Lines
}

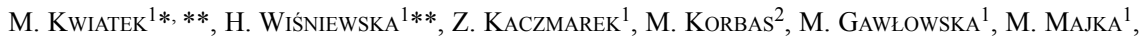 \\ K. PAnkiewicz ${ }^{1}$, J. Danielewicz ${ }^{2}$ and J. Belter ${ }^{1}$ \\ ${ }^{1}$ Institute of Plant Genetics Polish Academy of Science, Strzeszyńska 34, 60-479 Poznań, Poland \\ ${ }^{2}$ Institute of Plant Protection, National Research Institute, Władysława Węgorka 20, 60-318 Poznań, Poland
}

(Received 22 October 2014; Accepted 16 March 2015;

Communicated by X.F. Zhang)

\begin{abstract}
Pch1 gene translocated from Aegilops ventricosa provides effective resistance to eyespot in wheat. To track the $P c h 1$ gene introgression, we investigated 372 genotypes obtained from various breeding programs using endopeptidase $E p D 1 b$ marker, sequence-tagged-site (STS) marker XustSSR2001-7DL, and the score of infection index (K-index) evaluated after in vivo inoculation test. These genotypes were divided into three groups with 136, 124 and 112 genotypes for the field test lasting three years. In 2011, the mean K-index was 0.81, while 2012 and 2013 the mean K-indexes were 1.60 and 1.46, respectively. Both marker results indicated that 18 genotypes possessed Pchl gene. Statistical analysis of the level of K-index showed that these 18 genotypes were resistant to eyespot, which verified the proper assignment of wheat genotypes with Pch1 gene based on the marker data. Thus, the endopeptidase and XustSSR2001-7DL are useful for identifying sources of eyespot resistance gene Pch1 in wheat breeding program.
\end{abstract}

Keywords: endopeptidase, eyespot disease, inoculation tests, isozyme, STS marker, Triticum aestivum

\section{Introduction}

Eyespot (strawbreaker foot rot), caused by necrotrophic fungi Oculimacula yallundae (syn: Tapesia yallundae, Wallwork and Spooner) Crous and W. Gams and O. acuformis Crous and W. Gams (syn: T. acuformis) (Crous et al. 2003), is one of the most dangerous diseases of cereals in the temperate climate. It usually appears between winter and spring. Normally, Oculimacula acuformis and O. yallundae simultaneously appears on the field. First symptoms show up during the autumn pullulating. Eyespot causes characteristic eye-shaped lesions on the lower portion of the stem, which are clearly visible at BBCH 30-32 (Biologische Bundesanstalt, Bundessortenamt und CHemische Industrie - scale of phenological development stages of plants) (Korbas 2004). Severe eyespot lesions can

\footnotetext{
*Corresponding author; E-mail: mkwi@igr.poznan.pl; Phone: +48-61-65-50-220; Fax: +48-61-65-50-301

**These authors participated equally in the research
} 
weaken stem bases and cause them to bend or break, which could result in yield losses of up to 50\% (Fitt et al. 1988; Janczewska 1991; Murray 2010). Eyespot also results in reduced tiller number, kernel number per head, and 1000-kernel weight (Scott and Hollins 1974; Murray and Bruehl 1983). Moreover, it is hypothesized that eyespot reduced yield of winter wheat in two ways: direct losses caused by eyespot lesions that interfered with movement of water and nutrients through the stems and indirect losses caused by lodging that interfered with harvest (Glynne 1944). Winter cereals are more sensitive to eyespot infection than spring cereals because of favourable environmental conditions for infection during autumn and winter (Murray 2010).

Most of cultivated species of wheat are affected by eyespot including wheat (T. aestivum), durum (T. durum), Emmer (T. dicoccum), and spelt (T. spelta) (Sprague 1936). However, some related species or varietes of wheat such as Aegilops ventricosa (carrying Pch1 gene; Sprague 1936), Dasypyrum villosum (Pch3, Murray et al. 1994), Triticum tauschii (Yilldrim et al. 1995), Triticum aestivum cv. Capelle-Despez (Pch2; de la Pena et al. 1997) are reported to be completely resistant. Sprague (1936) suggested that eyespot resistant wheat breeding genotypes could be developed from hybrids of wheat and its wild relatives. Pch1 gene is commonly being used in both Europe and the USA because it is more effective in limiting disease development than Pch2 and is present in several hexaploid wheat varieties (Santra et al. 2006). The $P$ chl resistance gene was identified in Aegilops ventricosa $\left(2 \mathrm{n}=4 \mathrm{x}=28, \mathrm{D}^{\mathrm{V}} \mathrm{D}^{\mathrm{V}} \mathrm{M}^{\mathrm{V}} \mathrm{M}^{\mathrm{V}}\right)$ (Mena et al. 1992). First eyespot resistant wheat line "VPM1" was derived from a cross between an amphiploid (Ae. ventrico$s a \times$ T. persicum) and T. aestivum cv. "Marne" (Maia 1967). This was achieved because Ae. ventricosa possesses the genome $\mathrm{M}^{\mathrm{v}} \mathrm{M}^{\mathrm{v}} \mathrm{D}^{\mathrm{v}} \mathrm{D}^{\mathrm{v}}$, and therefore the $\mathrm{D}^{\mathrm{v}}$ chromosomes can pair with the D genome of wheat (Doussinault et al. 1983). The transferred sequence with the Pch1 gene has been mapped in chromosome arm 7DL (Jahier et al. 1978; McMillin et al. 1986; Worland et al. 1988). "VPM1" line was a base for breeders to create new resistance cultivars like "Rendezvous" (used in the presented work as a resistance standard).

Phenotyping for eyespot resistance in breeding programs requires replicated seedling bioassays and field trials. However, there is a high level of environmental variance often associated with seedling bioassays and field trials of eyespot (de la Peña et al. 1996; Lucas et al. 2000) and this can give rise to inaccuracies when determining the level of eyespot resistance within wheat breeding genotypes or varieties. Therefore, the development of molecular markers for eyespot resistance genes could improve efficiency and accuracy when selecting for eyespot resistance within plant breeding programs.

An identification of the Pchl locus is provided by closely linked endopeptidase gene locus EpD1b (McMillin et al. 1986; Worland et al. 1988; Groenewald et al. 2003). Endopeptidase-1 (Ep-1) in wheat is controlled by 3 loci: EpA1, EpB1 and EpD1, located in homoeologous chromosomes 7AL, 7BL and 7DL, respectively (Hart and Langston 1977; McMillin and Tuleen 1977, Koebner et al. 1988; Santra et al. 2006). EpD1 has two alleles: EpDla - derived from wheat and EpDIb - from Ae. ventricosa (Koebner et al. 1988). The close localization of EpD $1 b$ gene locus and $P c h 1$ gene locus determines utility of endopeptidase markers. Santra et al. (2006) reported that the endopeptidase marker is $100 \%$ accurate for predicting eyespot reaction in wheat. Groenewald et al. (2003) iden- 
tified the amplified fragment length polymorphism (AFLP) markers linked to the EpD1b and Pch1 and conversed one of them into PCR-based screening system. STS marker predicted disease reaction with approximately $90 \%$ accuracy (Santra et al. 2006). Further markers to the distal end of long arm of chromosome 7D are required for the fine mapping of Pchl (Chapman 2008). Wheat SSR markers, such as Xwmc14 (Somers et al. 2004) and Xbarc 97 (Shi et al. 2003), are often dominant, producing a specific product from wheat but failing to amplify one from the Ae. ventricosa introgression (Leonard et al. 2008).

The aim of this study was to identify the transferred fragment of Ae. ventricosa segment carrying eyespot resistance gene using genotyping and phenotyping methods. The present paper reports an effective identification of eyespot resistance in wheat breeding genotypes using enzymatic and molecular markers supplied by phenotypic evaluation under field control after inoculation.

\section{Materials and Methods}

\section{Plant materials}

372 breeding genotypes of wheat (Triticum aestivum L.), obtained in various breeding programs, designed to transfer the eyespot resistance to common wheat, were used in this study. We have analysed 136, 124 and 112 genotypes in the first, second and third year of the experiment, respectively. Triticum aestivum L. variety "Rendezvous" was used in as a resistance control. Three varieties of wheat ('Muszelka', 'Ozon' and 'Tonacja') without $P c h 1$ gene were used as susceptibility control. The results include data from series of 3 experiments with breeding genotypes of wheat, conducted over 3 successive years (20112013) at one place located in Kopaszewo Plant Breeding Station. All experiments were carried out in a complete randomized design in 4 replications using 50 plants per replication. The plant material was planted in $0.5 \mathrm{~m}^{2}$ plots consisted of 5 rows $(50 \mathrm{~cm} \mathrm{long})$.

\section{Pch1 markers analysis}

Six plants from each genotype were examined in endopeptidase and STS marker analysis. The endopeptidase assay was made using leaf tissue from two-week-old seedlings. The enzyme was extracted by grinding the leaves using a plexiglass bar in $10 \mu \mathrm{l}$ of $0.025 \mathrm{M}$ glycyl-glycine buffer ( $\mathrm{pH}$ 7.4; SIGMA). To load samples, paper strips were soaked in the enzyme extract for each genotype and inserted in to the gel. The $10 \%$ starch (SIGMA) gel was run at $4{ }^{\circ} \mathrm{C}$ at $200 \mathrm{~V}$. After electrophoresis the gel was incubated in the dark at $37^{\circ} \mathrm{C}$ for 30 minutes with $0.5 \%$ solution of low melting agarose containing $2.56 \mathrm{mg}$ Fast Black K Salt (SIGMA) and $1.12 \mathrm{mg} \mathrm{N}-\alpha$-Benzoyl-DL-Arginine-LB-Naphthylamide (BANA; SIGMA) in $0.1 \mathrm{M}$ Trizma maleate (SIGMA) - $\mathrm{NaOH}$ (pH 5.8; POCH). The gels were visualized using Canon PowerShot G9 camera.

The identification of STS marker XustSSR2001-7DL (Groenewald et al. 2003) was made using the same leaf tissue that have been used for the endopeptidase assay. Total genomic DNA was extracted from 14-day-old seedlings using CTAB method according 
to Doohan et al. (1998). The marker was amplified following the protocol of Groenewald et al. (2003). The PCR profile was modified with reference to standard protocol and consisted of denaturation at $94{ }^{\circ} \mathrm{C}$ for $10 \mathrm{~min}$., followed by 35 cycles of $94{ }^{\circ} \mathrm{C}$ for $30 \mathrm{~s}, 55^{\circ} \mathrm{C}$ for $30 \mathrm{~s}$ and $72{ }^{\circ} \mathrm{C}$ for $1 \mathrm{~min}$., followed by final extension for $10 \mathrm{~min}$. at $72{ }^{\circ} \mathrm{C}$ and a soak temperature of $4{ }^{\circ} \mathrm{C}$. The products of amplification were visualized using $3 \%$ agarose (SIGMA) gel $(1 \times$ TBE buffer, $5 \mathrm{~h}$ at $100 \mathrm{~V})$ stained with ethidium bromide.

\section{Evaluation of the Pch1 gene expression under field conditions}

All wheat genotypes and control variety observed in field experiment were inoculated by spraying at BBCH 31-32 with a fresh-made conidial-mycelium suspension of Oculimacula acuformis and $O$. yallundae $\left(1: 1 \mathrm{ratio}, 4 \times 10^{6} \mathrm{spores} / \mathrm{ml}\right)$. Plant material was harvested and than the level of the disease was scored in the Department of Mycology (Institute of Plant Protection, National Research Institute). Only eyespot symptoms were rated. Sample of 50 plants from each of 4 replicate plots of wheat genotypes and control varieties were evaluated (in a total 200 leaf sheaths from each genotype). The percent of infected leaf sheaths was determine and the leaf sheath infection index was calculated. The level of the leaf sheath sample infection scale was measured using I-IV scale (Fig. S1*).

\section{Statistical analysis}

The K-index results form each of four replications were averaged. In the first step, the fundamental statistical characteristics for 4 groups of genotypes: 1) one resistant variety 'Rendezvous', which was a resistance control; 2) a group of genotypes with EpD1b and 240 bp STS marker product, assigned as 'Pch1+'; 3) a group of genotypes with another types of zymograms and 222 bp product of STS marker called 'Pch1-' and 4) a group of standard breeding varieties ('Muszelka', 'Ozon' and 'Tonacja'), which was consider as a susceptibility control. The groups were calculated for each year of experiment. Singlefactor analysis of variance with 3 years $\times 4$ groups of genotypes $=12$ groups was used for all experiments jointly to examine the differences between distinguished groups of wheat genotypes with regard to the $\mathrm{K}$-index value. All hypotheses about the equality of genotype groups were tested at $P=0.05$ and $P=0.01$ significance level. After the rejection of the sensual hypothesis of no differences between groups, the least significance difference $\left(\mathrm{LSD}_{0.05}\right.$ and $\left.\mathrm{LSD}_{0.01}\right)$ test for unequal replications was used for the planned pair comparisons and F-test for studying of significance of various contrasts between groups (Gomez and Gomez 1984).

\section{Results}

The zymograms observed among 372 genotypes were grouped into 6 classes (I to VI) according to Santra et al. (2006) (Table 1). 18 genotypes and 'Rendezvous' resulted in the type-I zymogram, that possessed the top band for Ep-D1b and the middle band

*Further details about the Electronic Supplementary Material (ESM) can be found at the end of the article. 
Table 1. Endopeptidase zymogram types and the number of genotypes representing given type

\begin{tabular}{|c|c|c|c|c|c|c|}
\hline \multirow{2}{*}{ Bands } & \multicolumn{6}{|c|}{ Endopeptidase zymogram types } \\
\hline & I & II & III & IV & $\mathrm{V}$ & VI \\
\hline$E p D 1 b$ & - & & - & - & - & \\
\hline middle & - & - & - & & & - \\
\hline EpDla & & - & - & & - & \\
\hline \multicolumn{7}{|c|}{ number of genotypes ( $\mathrm{K}$ index range) } \\
\hline 2011 & $8(0.00-0.19)$ & $96(0.00-2.5)$ & $8(0.06-1.09)$ & $9(0.25-3.01)$ & $15(0.31-1.88)$ & $\mathrm{n} / \mathrm{a}$ \\
\hline 2012 & $6(0.00-3.75)$ & $21(0.38-7.75)$ & $76(3.75-5.33)$ & $\mathrm{n} / \mathrm{a}$ & $21(0.00-6.67)$ & $\mathrm{n} / \mathrm{a}$ \\
\hline 2013 & $4(0.00-0.76)$ & $15(0.89-2.94)$ & $79(0.00-4.44)$ & $\mathrm{n} / \mathrm{a}$ & $14(0.69-2.63)$ & $\mathrm{n} / \mathrm{a}$ \\
\hline $\begin{array}{l}\text { Total } \\
\text { number of } \\
\text { genotypes }\end{array}$ & $18(0.00-3.75)$ & $\begin{array}{c}132 \\
(0.00-7.75)\end{array}$ & $\begin{array}{c}163 \\
(0.00-5.33)\end{array}$ & $9(0.25-3.01)$ & $50(0.00-6.67)$ & $\mathrm{n} / \mathrm{a}$ \\
\hline
\end{tabular}

‘-' band position on starch gel.

(Fig. S2a, b). The type-II zymogram, with the middle band and the bottom band for EpDla was identified in 132 genotypes and 3 standard varieties ('Muszelka', 'Ozon' and 'Tonacja'). The type-III zymogram, with all three bands was founded in 163 genotypes (Fig. S2a, b). Isoenzymatic assay in the plants of 9 genotypes resulted in identification of the type-IV zymogram with only the top band for $E p-D 1 b$. The type-V zymogram had the top band for $E p-D 1 b$ and the bottom band for Ep-Dla and was recognized in 50 genotypes (Fig. S2a, b). The type-VI zymogram with only the middle band was not present in evaluated genotypes.

The XustSSR2001-7DL marker profiles of the 372 genotypes were analyzed for the presence of either a 222- or 240-bp band (Fig. S2c). The results showed that STS marker amplified the $240 \mathrm{bp}$ fragment in all of the 18 genotypes with the type-I zymogram pattern (Fig. S2). The same type of zymogram and size of the STS band was obtained for the standard of resistance - Rendezvous. The other 354 genotypes had 222 bp band. The percentage of the genotypes with EpDIb and $240 \mathrm{bp}$ band in relation to all examined genotypes was less than $5 \%$.

Hence, leaving aside the resistance standard ('Rendezvous') and standard varieties ('Muszelka', 'Ozon' and 'Tonacja'), two groups of genotypes were distinguished in each experiment as a result of isoenzymatic and molecular analysis. Genotypes from one group resulted in Type-I zymogram, which is assigned for endopeptidase EpD1b; and 240bp band in STS marker analysis. This group, called 'Pch1+' contained: 8 genotypes in 2011, 6 genotypes in 2012 and 4 genotypes in 2013. Genotypes from another group resulted in other types of zymograms and 222bp band in STS marker tests. This group, called 'Pch1-' was represented by 128 genotypes in 2011, 118 genotypes in 2012 and 108 genotypes in 2013.

The harvest after spraying the suspension of Oculimacula acuformis and O. yallundae mycelium was analyzed. Inoculation tests allows determining the leaf sheath infection K-index (Table S1). The leaf sheath infection K-index was low for the 74 genotypes 
$(\mathrm{K}=0.00-0.5)$ and very high for the 24 genotypes $(\mathrm{K}=3.0-7.75)$. The range of the infection was lower in 2011 in comparison with 2012 and 2013. Furthermore, in the first experimental year (2011), the mean K-index was 0.81 while in the 2012 and in the 2013 the mean K-indexes were 1.60 and 1.46 , respectively.

Four groups of genotypes: one resistant variety 'Rendezvous' (which was a resistance control); a group carrying Pch1 gene; a group of genotypes without Pch1 gene and a group of standard varieties ('Muszelka', 'Ozon' and 'Tonacja') were distinguished basing on the zymograms and STS marker results (Table S1). The least significance test with unequal replication $\left(\mathrm{LSD}_{0.05}\right.$ and $\mathrm{LSD}_{0.01}$ ) used for the comparisons of four distinguished genotype groups showed that there was no significant differences between $\mathrm{K}$-index means of 'Rendezvous' when comparing the data from 2011 with data from 2012, and then 2011 with 2013, and 2012 with 2013 (Table S2). Similar dependency was observed among K-index means of 'Pch1+' genotypes, 'Pch1-' genotypes and standard varieties ('Muszelka', 'Ozon' and 'Tonacja'). The results of testing the differences between different genotype groups in particular years and the contrast groups for 3 years jointly are shown in Table S3. Comparing analysis of the K-index means of 'Rendezvous' with the K-index means of 'Pch1+' genotypes, regarding the year of experiment, showed that there were no differences between the means at $P=0.05$ and $P=0.01$ significance level (Table S3). The parallel comparison of K-index means of 'Pch1-' genotypes with K-index means of standard varieties also resulted in the lack of differences at $P=0.05$ and $P=0.01$ significance level (Table S3). However, considering the comparison between the K-index means of 'Rendezvous' with the K-index means of 'Pch1-' genotypes with regard of the year of experiment, it can be assumed that there is no significant differences in the 2011 , but in the 2012 differences are significant at $P=0.05$. Moreover, in the 2013 year the differences are significant at both $P=0.05$ and $P=0.01$. Considering the $\mathrm{K}$-index means of 'Rendezvous' compared to standard varieties, there were no differences in the 2011 , but in the 2012 the differences at $P=0.05$ were observed and in the 2013 the differences were significant at $P=0.01$. Finally, the least significance test with unequal replication used for the comparisons of the group of 'Pch1+' genotypes with the group of 'Pch1-' genotypes showed that the differences in the 2011 were significant at $P=0.05$, and in the 2012 and 2013 the differences were significant at $P=0.01$.

\section{Discussion}

There is an exiguous number of sources of Pchl gene resistance to eyespot disease in wheat. The most of existing, resistant varieties were developed using VPM-1 line reported by Maia et al. (1967). Although Pchl has been widely used as a source of resistance in attempts to produce eyespot resistant cultivars, the use of Pchl in commercial cultivars has been limited as the resistance gene is transferred to wheat from Ae. ventri$\cos a$ as part of a segment of chromosome $7 \mathrm{D}^{\mathrm{v}}$ along with undesirable genes from the wild grass. Hence, a significant yield reduction may sometimes be observed in the absence of the disease (Koen et al. 2002), like in Pch1 bearing variety 'Rendezvous'. Although it contained both Pch1 and a second gene, supposed to be Pch2, and provided a higher 
Table 2. Statistical characteristics of four distinguished groups of genotypes: one resistant variety 'Rendezvous', which was a resistance control; a group of genotypes carrying Pch1 gene (Pch+); a group of genotypes without Pchl gene (Pch-) and a group of standard varieties ('Muszelka', 'Ozon' and 'Tonacja') with regard to $\mathrm{K}$-index value in each year of experiment

\begin{tabular}{|c|c|c|c|c|c|c|}
\hline $\begin{array}{c}\text { Year of } \\
\text { experiment }\end{array}$ & Group of genotypes & $\begin{array}{c}\text { Number of } \\
\text { genotypes }\end{array}$ & $\begin{array}{l}\text { Mean K-index } \\
\text { score }\end{array}$ & $\begin{array}{l}\text { Standard } \\
\text { deviation }\end{array}$ & $\begin{array}{l}\text { Minimal } \\
\text { K-index }\end{array}$ & $\begin{array}{c}\text { Maximal } \\
\text { K-index }\end{array}$ \\
\hline \multirow{4}{*}{2011} & Rendezvous & 1 & 0.06 & 0.010 & 0.05 & 0.07 \\
\hline & $\operatorname{Pch}+$ & 8 & 0.10 & 0.068 & 0.00 & 0.19 \\
\hline & Pch- & 128 & 0.88 & 0.556 & 0.00 & 3.01 \\
\hline & Standard varieties & 3 & 0.61 & 0.371 & 0.31 & 1.13 \\
\hline \multirow{4}{*}{2012} & Rendezvous & 1 & 0.43 & 0.130 & 0.30 & 0.56 \\
\hline & $\operatorname{Pch}+$ & 6 & 0.65 & 0.614 & 0.00 & 1.50 \\
\hline & Pch- & 118 & 1.64 & 1.070 & 0.00 & 7.75 \\
\hline & Standard varieties & 3 & 1.96 & 1.392 & 0.58 & 3.89 \\
\hline \multirow{4}{*}{2013} & Rendezvous & 1 & 0.06 & 0.020 & 0.04 & 0.08 \\
\hline & $\mathrm{Pch}+$ & 4 & 0.25 & 0.347 & 0.00 & 0.76 \\
\hline & Pch- & 108 & 1.49 & 0.925 & 0.00 & 4.44 \\
\hline & Standard varieties & 3 & 2.15 & 0.921 & 0.94 & 3.11 \\
\hline
\end{tabular}

level of resistance than any previous wheat cultivar (Hollins et al. 1988), the variety was not widely used as a result of its relatively low yield. This association between Pch1 and yield limitations has proven difficult to break because of limited recombination of the translocated Ae. ventricosa segment (Johnson 1992).

The aim of this study was to track the $P$ chl gene introgression in a collection of hexaploid wheat breeding genotypes. 18 genotypes carried both $E p D 1 b$ endopeptidase marker and $240 \mathrm{bp}$ product of XustSSR2001-7DL marker amplification. Those genotypes were also slightly infected after inoculation tests (Table 2). The level of infection after the inoculation tests was calculated using K-index formula (Fig. S1), which consider the percentage of infected area of leaf sheaths. This manner seems to be more opinion-forming, than common visual evaluation scale. The range of the infection in 2011 was low in comparison with the results from 2012 and 2013 because of the weather conditions (low temperatures in winter and spring, data not shown), which have not been conductive to proper development of the pathogens. This dependency was confirmed by the least significance test with unequal replication $\left(\mathrm{LSD}_{0.05}\right.$ and $\left.\mathrm{LSD}_{0.01}\right)$, used for the planned pair comparisons (Table S3). It showed no significant differences between K-index means of 'Rendezvous' compared to a group of susceptible genotypes ('Pch1-') and standard varieties (established by isoenzymatic and molecular tests). The 18 of 386 genotypes were described as resistant, regarding to isoenzymatic/molecular assays and in vivo tests. Therefore, the genotypes that do exhibit high levels of resistance are considered to be worthwhile of further study. The results also showed that the endopeptidase marker and 
the STS marker were useful for predicting eyespot reaction in this set of wheat genotypes. However in case of group of susceptible genotypes ('Pch1-') characterized by a low level of infection there is possibility that the linkage between Pch1 and markers was broken. If such a situation occurred, these lines might possess Pchl gene without the linked markers, which might lead to false negative results. Notwithstanding, the low K-index (even $\mathrm{K}=0$ ) results in some 'Pch1-'genotypes (Tables 2 and $\mathrm{S} 1$ ) suggest that other genetic factors could have an influence on the expression of the eyespot resistance. The present analysis focused only on evaluating the Pch1 gene introgression in given 372 lines. However, these genotypes were obtained in various crossing combinations, where eyespot tolerant wheat genotypes or varieties were chosen as parental components. Those components might carry unknown resistance genes that could be the reason of limited infection showed by low K-index results of genotypes without Pchl gene.

Presented results confirmed the information about endopeptidase assay of wheat genotypes in previous reports (McMillin et al. 1986; Santra et al. 2006). In the analyzed breeding genotypes, there were a set five of six known types of banding patterns (Table 1) according to Santra et al. (2006). The type-VI pattern (with the appearance of a sole, middle band) has not been identified. Like in the study of Santra et al. 2006, it was shown that presence of bands for locus $E p-D 1 b$ and the middle band, without bands for Ep-Dla (type-I zymogram, Table 1) is related to complete resistance to eyespot disease. Moreover, Santra et al. (2006) pointed, that the middle band has no direct effect on the response to infection. It was found as mix of $E p-A 1$ and $E p-B 1$ products migrant together in starch gel, which prooved the fact, that loci $E p-A 1$ and $E p-B 1$ are located in chromosomes 7AL and $7 \mathrm{BL}$ respectively, what was confirmed in our study. However, there was a difference in interpreting the genotypes characterized by type-IV zymogram. Santra et al. (2006) recognized type-IV zymogram varietes (Coda, Tubbs, Beamer and Mohler) as resistant ones, but the XustSSR2001-7DL marker analysis showed the differentiation in amplified fragments (222bp; 222bp and 240bp; 240bp, respectively). In our study, the genotypes characterized by type-IV zymoram had only the 222 bp product of amplification using primers for XustSSR2001-7DL. Moreover, the range of K-index (0.25-3.01), calculated after the inoculation tests, showed that these genotypes were much more infected than 'Rendezvous' and genotypes characterized by type-I zymogram (K-index range: 0-0.19), What is more 3.01 score of $\mathrm{K}$-index was the highest in this year of experiment (Table 2). On this basis, those nine genotypes (type-IV zymogram pattern) were not considered as resistant ones.

With regard to our results we concluded that endopeptidase marker EpD1b, STS marker XustSSR2001-7DL and phenotypic evaluation under field conditions after inoculation can be used in the breeding programs to identify the sources of resistance for eyespot determined by Pch1 gene.

\section{Acknowledgement}

This work was financed by the Ministry of Agronomy and Rural Development (HOR hn $-801-11 / 13)$. 


\section{Authors' Contribution and Conflict of Interest}

M. Kwiatek and H. Wiśniewska participated equally in the research. H. Wiśniewska initiated the project and designed the study. M. Kwiatek, M. Majka, M. Gawłowska, K. Pankiewicz and J. Belter performed the markers analysis. M. Korbas and J. Danielewicz carried out the in vivo tests. Z. Kaczmarek made the statistical analysis. M. Kwiatek wrote the paper. The authors declare that they have no conflict of interest.

\section{References}

Chapman, N.H., Burt, C., Dong, H., Nicholson, P. 2008. The development of PCR-based markers for the selection of eyespot resistance genes Pch1 and Pch2. Theor. Appl. Genet. 117:425-433.

Crous, P.W., Groenewald, J.Z.E., Gams, W. 2003. Eyespot of cereals revisited. Its phylogeny reveals new species relationships. Eur. J. Plant Pathol. 109:841-850.

de la Peña, R.C., Murray, T.D., Jones, S.S. 1996. Linkage relations among eyespot resistance gene Pch2, endopeptidase Ep-A1b, and RFLP marker Xpsr121 on chromosome 7A of wheat. Plant Breeding 115:273-275.

de la Peña, R.C., Murray, T.D., Jones, S.S. 1997. Identification of an RFLP interval containing Pch2 on chromosome 7AL of wheat. Genome 40:249-252.

Doohan, F.M., Parry, D.W., Jenkinson, P., Nicholson, P. 1998. The use of species-specific PCR-based assays to analyse Fusarium ear blight of wheat. Plant Pathol. 47:197-205.

Doussinault, G., Delibes, A., Sanchez-Monge, R., Garcia-Olmedo, F. 1983. Transfer of a dominant gene for resistance to eyespot disease from a wild grass to hexaploid wheat. Nature 303:698-700.

Fitt, B.D.L., Goulds, A., Pollet, R.W. 1988. Eyespot (Pseudocercosporella herpotrichoides) epidemiology in relation to prediction of disease severity and yield loss in winter wheat; a review. Plant Pathol. 37:311-328.

Glynne, M.D. 1944. Eyespot, Cercosporella herpotrichoides Fron, and lodging of wheat. Ann. Appl. Biol. 31:377-378.

Gomez, K.A., Gomez, A.A. 1984. Statistical Procedures for Agricultural Research. 2nd ed. J. Wiley. New York, USA.

Groenewald, J.Z., Marais, A.S., Marais, G.F. 2003. Amplified fragmentlength polymorphism-derived microsatellite sequence linked to the Pch1 and Ep-D1 loci in common wheat. Plant Breeding 122:83-85.

Hart, G.E., Langston, P.J., 1977. Chromosomal location and evolution of isozyme structural genes in hexaploid wheat. Heredity 39:263-277.

Hollins, T.W., Lockley, K.D., Blackman, J.A., Scott, P.R., Bingham, J. 1988. Field performance of Rendezvous, a wheat cultivar with resistance to eyespot (Pseudocercosporella herpotrichoides) derived from Aegilops ventricosa. Plant Pathol. 37:251-260.

Jahier, J., Doussinault, G., Dosba, F., Bourgeois, F. 1978. Monosomic analysis of resistance to eyespot in the variety „Roazon” In: Ramanujam, S. (ed.), Proc. of the 5th Int. Wheat Genet. Symp. Indian Agricultural Research Institute. New Dehli, India. pp. 437-440.

Janczewska, A. 1991. Yield loss of winter wheat as influenced by the intensity of Pseudocercosporella herpotrichoides (Fron.) attack. Phytopathologia Polonica 1(XIII):41-44.

Johnson, R. 1992. Past, present and future opportunities in breeding for disease resistance, with examples from wheat. Euphytica 63:3-22.

Koebner, R.M.D., Miller, T.E., Snape, J.W., Law, C.N. 1988. Wheat endopeptidase: genetic control, polymorphism, intrachromosomal gene location, and alien variation. Genome 30:186-192.

Koen, E., Labuschagne, M.T., Viljoen, C.D. 2002. The influence of eyespot resistance genes on baking quality and yield in wheat. J. of the Science of Food and Agric. 82:1537-1540.

Korbas, M., 2004. Choroby i szkodniki zbóż (Diseases and pests of cereals). Multum. Poznań, Poland

Leonard, J.M., Watson, C.J.W., Carter, A.H., Hansen, J.L., Zemetra, R.S., Santra, D.K., Campbell, K.G., RieraLizarazu, O. 2008. Identification of a candidate gene for the wheat endopeptidase Ep-D1 locus and two other STS markers linked to the eyespot resistance gene Pch1. Theor. Appl. Genet. 116:261-270. 
Lucas, J.A., Dyer, P.S., Murray, T.D. 2000. Pathogenicity, host specificity, and population biology of Tapesia spp., causal agents of eyespot disease in cereals. Advances in Bot. Res. 33:226-258.

Maia, N. 1967. Obtention de blés tendres résistants au piétin-verse par croisements interspécifiques blés $\times$ Aegilops. (Obtaining soft wheat resistant to eyespot by interspecific crosses wheat $\times$ Aegilops) Comptesrendus des Seances de l'Academie d'Agriculture de France (Reports of the France Academy of Agriculture) 53:149-154.

McMillin, D.E., Tuleen, N.A. 1977. Determination of the linkage relationships and the gene centromere genetic distances for endopeptidase structural genes in hexaploid wheat. Genetics 86(Suppl.):44.

McMillin, D.E., Allan, R.E., Roberts, D.E., 1986. Association of an isozyme locus and strawbreaker foot rot resistance derived from Aegilops ventricosa in wheat. Theor. Appl. Genet. 72:743-747.

Mena, M., Doussinault, G., Lopez-Brana, I., Aguaded, S., Garcia-Olmedo, F., Delibes, A., 1992. Eyespot resistance gene Pch-1. H-93 wheat lines. Evidence of linkage to markers of chromosome group 7 and resolution from the endopeptidase locus Ep-D1b. Theor. Appl. Genet. 83:1044-1047.

Murray, T.D. 2010. Eyespot (Strawbreaker foot rot). In: Bockus, W.W., Bowden, R.L., Hunger, R.M., Murray, T.D., Smiley, R.W., Morrill, W. (eds), Compendium of Wheat Diseases and Insects. Third Ed. APS Press. Minneapolis, MN, USA. pp. 32-34.

Murray, T.D., Bruehl, G.W. 1983. Role of hypodermis and secondary cell wall thickening in basal stem internodes in resistance to strawbreaker foot rot in winter wheat. Phytopathol. 73:261-268.

Santra, D.K., Watt, C., Little, L., Kidwell, K.K., Campbell, K.G. 2006. Comparison of a modified assay method for the endopeptidase marker Ep-D1b with the Sequence Tag Site marker XustSSR2001-7DL for strawbreaker foot rot resistance in wheat. Plant Breeding 125:13-18.

Scott, P.R., Hollins, T.W. 1974. Effects of eyespot on yield of winter wheat. Ann. Appl. Biol. 78:269-279.

Shi, J.R., Song, Q.J., Singh, S., Lewis, J., Ward, R.W., Cregan, P., Gill, B.S. 2003. Genetic and physical maps of XBARC SSR loci in wheat. In: Proc. 2003 Natl. Fusarium Head Blight. http://www.scabusa.org/, pp. $41-45$.

Somers, D.J., Isaac, P., Edwards, K. 2004. A high density microsatellite consensus map for bread wheat (Triticum aestivum L.). Theor. Appl. Genet. 109:1105-1114.

Sprague, R. 1936. Relative susceptibility of certain species of Gramineae to Cercosporella herpotrichoides. J. of Agric. Res. 53:659-670.

Worland, A.J., Law, C.N., Hollins, T.W., Koebner, R.M.D., Giura, A. 1988. Location of a gene for resistance to eyespot (Pseudocercosporella herpotrichoides) on chromosome 7D of bread wheat. Plant Breeding 101:4351.

Yildirim, A., Jones, S.S., Murray, T.D., Cox, T.S., Line, R.F. 1995. Resistance to stripe rust and eyespot diseases of wheat in Triticum tauschii. Plant Disease 79:1230-1236.

\section{Electronic Supplementary Material (ESM)}

Electronic Supplementary Material (ESM) associated with this article can be found at the website of CRC at http://www.akademiai.com/content/120427/

Electronic Supplementary Table S1. Genotypes and phenotypes of given 372 genotypes of wheat

Electronic Supplementary Table S2. The least significance difference (LSD) tests for genotype groups in particular years at $P=0.05$ and $P=0.01$

Electronic Supplementary Table S3. Estimates and results of testing the significance differences between groups of genotypes with regard to $\mathrm{K}$-index values

Electronic Supplementary Figure S1. K-index formula. I - no symptoms, II - less than 50\% of leaf sheaths surface infected, III - over $50 \%$ of leaf sheaths surface infected, IV - $100 \%$ of leaf sheaths surface infected, rotten tissue 
Electronic Supplementary Figure S2. (a) Endopeptidase zymogram, (b) zymogram banding pattern, and (c) amplified products for the STS marker XustSSR2001-7DL of (1) 'Rendezvous' - resistance standard, (2-5) susceptible wheat lines. (L) DNA size ladder. Amplified 222 bp or 240 bp products indicate eyespot susceptibility or resistance, respectively 